DOI: https://doi.org/10.15688/re.volsu.2019.3.9

UDC 332.1

Submitted: 14.04.2019

LBC 650.049-551

Accepted: 28.05.2019

\title{
ECONOMIC SECURITY OF THE REGION: EVALUATION AND SECURITY MECHANISMS ${ }^{1}$
}

\author{
Marina E. Buyanova \\ Volgograd State University, Volgograd, Russian Federation \\ Irina S. Averina \\ Volgograd State University, Volgograd, Russian Federation \\ Alina S. Kulakova \\ Volgograd State University, Volgograd, Russian Federation
}

\begin{abstract}
Modern globalization processes cause the emergence of new threats to society, and necessitate the development of innovative mechanisms to overcome them in order to improve the level of security at various levels of management. The objective of this study is to test the methodology for assessing the level of security of the economic system of the region (based on the use of an integral indicator), as well as the definition of mechanisms for its provision at the meso-level. The structure of this indicator includes aspects of the impact on the stability of the system of the following factors (market, non-market and social ones), based on the system of indicators (the number of employed population, the cost of technological innovation per capita, investment in fixed capital, etc.). The calculation of summary indicators is given on the example of one of the subjects of the Russian Federation (Volgograd region), which allowed to determine negative changes in the level of economic security in the region (significant technological backwardness, consistent depletion of natural resources, growth of budget commitments, etc.). Due to the comprehensive assessment, a list of factors that cause this condition has been identified with the aim of further targeted impact from public authorities to overcome the negative trends in the economic system of the region and (or) leveling their consequences. The development of mechanisms to ensure the economic security of the region, based on the above-mentioned method of integrated assessment, allows not only to fully assess the state of the regional economy, but also to identify the potential to strengthen the position of the entity of the country both at the national and international arena.
\end{abstract}

Key words: region, economic security, challenges, threats, indicators, threshold values of indicators, mechanisms to ensure, regional economy.

Citation. Buyanova M.E., Averina I.S., Kulakova A.S., 2019. Economic Security of the Region: Evaluation and Security Mechanisms. Regionalnaya ekonomika. Yug Rossii [Regional Economy. South of Russia], vol. 7, no. 3, pp. 83-93. (in Russian). DOI: https://doi.org/10.15688/re.volsu.2019.3.9

УДК 332.1

Дата поступления: 14.04.2019

ББК 650.049-551

Дата принятия: 28.05.2019

\section{ЭКОНОМИЧЕСКАЯ БЕЗОПАСНОСТЬ РЕГИОНА: ОЦЕНКА И МЕХАНИЗМЫ ОБЕСПЕЧЕНИЯ ${ }^{1}$}

\author{
Марина Эдуардовна Буянова
}

Волгоградский государственный университет, г. Волгоград, Российская Федерация

(С) Буянова М.Э., Аверина И.С., Кулакова А.С., 2019 
M.E. Buyanova, I.S. Averina, A.S. Kulakova. Economic Security of the Region: Evaluation and Security Mechanisms

\title{
Ирина Сергеевна Аверина
}

Волгоградский государственный университет, г. Волгоград, Российская Федерация

\section{Алина Сергеевна Кулакова}

Волгоградский государственный университет, г. Волгоград, Российская Федерация

\begin{abstract}
Аннотация. Современные глобализационные процессы вызывают появление новых угроз, образующихся перед обществом, и обусловливают необходимость выработки инновационных механизмов по их преодолению с целью повышения уровня безопасности на различных уровнях хозяйствования. Задачей данного исследования является апробация методики оценки уровня безопасности экономической системы региона (на основе применения интегрального показателя), а также определение механизмов ее обеспечения на мезоуровне. Структура упомянутого показателя включает в себя аспекты влияния на устойчивость системы следующих факторов (рыночных, нерыночных и социальных), базирующихся на системе индикаторов (численность занятого населения, затраты на технологические инновации на душу населения, инвестиции в основной капитал и т. д.). Расчет сводных индикаторов приведен на примере одного из субъектов Российской Федерации (Волгоградской области), что позволило определить негативные изменения уровня экономической безопасности в данном регионе (значительная технологическая отсталость, последовательное истощение природных ресурсов, рост бюджетных обязательств и т. д.). Благодаря комплексной оценке выявлен перечень факторов, обусловливающих указанное состояние, с целью дальнейшего целенаправленного воздействия со стороны органов государственной власти по преодолению отрицательных тенденций в хозяйственной системе региона и (или) нивелированию их последствий. Разработка механизмов обеспечения экономической безопасности региона, базирующаяся на вышеупомянутой методике интегральной оценки, позволяет не только всесторонне оценить состояние регионального хозяйства, но и обозначить потенциал к усилению позиций субъекта страны как на национальной, так и международной арене.
\end{abstract}

Ключевые слова: регион, экономическая безопасность, вызовы, угрозы, индикаторы, пороговые значения индикаторов, механизмы обеспечения, экономика региона.

Цитирование: Буянова М. Э., Аверина И. С., Кулакова А. С., 2019. Экономическая безопасность региона: оценка и механизмы обеспечения // Региональная экономика. Юг России. Т. 7, № 3. С. 83-93. DOI: https://doi.org/ 10.15688/re.volsu.2019.3.9

\section{Введение}

Значимость исследования экономической безопасности регионов России не вызывает сомнений, более того, фиксируется в стратегии национальной безопасности Российской Федерации [Указ Президента РФ № 683, 2015]. Также важность исследования региональной экономической безопасности связана с тенденцией к дифференциации регионов по уровню экономического развития ввиду внешних и внутренних угроз.

Поскольку региональные экономики неоднородны, то они не способны одинаково противостоять внешним и внутренним угрозам. Поэтому важнейшей задачей со стороны государства для обеспечения своей экономической безопасности является уменьшение диапазона в уровнях развития регионов. Это особенно подчеркивается в стратегии национальной безопасности Российской Федерации: «Одним из главных направлений обеспечения национальной безопасности на региональном уровне (на среднесрочную перспективу) является создание механизма сокращения уровня межрегиональной дифференциации в социально-экономическом развитии субъектов Российской Федерации путем сбалансированного территориального развития страны, устранения инфраструктурных ограничений, введения механизма координации размещения транспортной, инженерной и социальной инфраструктур всех уровней, совершенствования системы стратегического и территориального планирования, обеспечения взаимной согласованности отраслевого и территориального развития, совершенствования национальной системы расселения и системы размещения производительных сил на территории Российской Федерации» [Указ Президента РФ № 683, 2015].

Актуальность данной работы определяется реализацией первого этапа Стратегии экономической безопасности России на период до 2030 г. [Указ Президента РФ № 208, 2017], который подразумевает разработку и реализацию различных мер, в том числе методического характера, в целях обеспечения экономической безопасности, совершенствования механизмов мониторинга и оценки ее состояния. Необходимость разработки методики оценки экономической безопасности на региональном уровне обусловлена различиями в системах управления стра- 
ной и регионом, а также в специфических угрозах региона. Кроме того, методология оценки экономической безопасности не разработана и не утверждена на государственном уровне, что дает базу для исследований многим ученым.

\section{Сущность и содержание понятия «экономическая безопасность региона»}

Существует множество подходов к определению экономической безопасности региона. Многие подходы основаны на выделении экономической безопасности региона в качестве структурного элемента национальной безопасности. На наш взгляд, такой подход является наиболее применимым в правотворческом контексте и используется больше в национальных правовых актах. Авторам статьи наиболее интересно определение данного понятия именно с точки зрения экономической науки.

Наиболее емкое и распространенное определение было предложено рядом авторов во главе с В.В. Криворотовым: «экономическая безопасность региона есть комплекс мер, направленных на устойчивое, постоянное развитие и совершенствование экономики региона, включающий механизм противодействия внешним и внутренним угрозам» [Криворотов, Калина, Эриашвили, 2011: 126]. Вместе с тем данное определение не учитывает структурные особенности экономической безопасности, а также не отражает наиболее важные критерии устойчивости региона.

Вызывает интерес концепция И.Н. Петренко, который в работе «Безопасность экономического пространства хозяйствующего субъекта» выдвигает понятие «безопасности экономического пространства региона» [Петренко, 2005], подразумевая под ним «состояние экономического потенциала, внутренней структуры и системы управления, обеспечивающие эффективность использования природных, трудовых, материальных и финансовых ресурсов, гарантированную защищенность региона от негативных изменений внешних условий, сохранение конкурентоспособности и адаптация к меняющимся условиям и границам его экономического пространства» [Петренко, 2005: 146-147]. Данное определение очень точечно описывает экономическую безопасность на уровне региона, а также содержит в себе условия ее оценки, что является его достоинством.

Экономическая безопасность региона должна включать в рассмотрение существенную особенность региональной структуры, выраженной в множественности структурных элементов [Криворотов, Калина, Эриашвили, 2011: 115]. Так, обеспечивая экономическую безопасность на уровне каждого структурного элемента, можно добиться ее целостности. Все структурные элементы находятся в тесной взаимосвязи и взаимозависимости, что определяет их неразрывность и необходимость совместного устойчивого развития. Наиболее важными структурными элементами являются: количественная характеристика населения; природно-ресурсный блок; предпринимательская среда; социальная подсистема; духовная сфера; управленческий блок.

Каждой из названных подсистем характерны свойства самоорганизации и автономии, но при этом между собой они плотно взаимодействуют, что делает их неотрывными от общего понимания экономики региона.

В качестве основного элемента региональной системы выступает население, представляющее трудовые ресурсы региона. Их наличие (недостаток или избыток) определяет развитие производств и сферы обслуживания в регионе. Также население является основным потребителем товаров и услуг, в свою очередь, они могут стимулировать производственную и непроизводственную сферы. От уровня дохода населения зависит и их инвестиционная способность, а как следствие, и объем инвестиций в регионе.

Природно-ресурсная подсистема выстраивает фундамент региона, во многом влияя на его специализацию. Состав этих ресурсов и цикличность их обработки определяет и характер территориальной организации населения, и ритм его жизни. Так, например, если регион специализируется на сельскохозяйственной промышленности, то основная работа будет производиться в период плодородия почв. Кроме того, объемы и эффективность ресурсодобывающих и обрабатывающих предприятий влияет на воспроизводственные процессы в регионе.

Предпринимательская подсистема является базисом региональной экономики. Ядром подсистемы являются отрасли по специализации региона. Именно благодаря специализации производства осуществляется обмен в пределах национальной экономики. Но существуют предприятия, обладающие либо высоким уровнем специализации, таким, что его продукция уникальна для мирового рынка, или развитостью производственного процесса, что также выделяет продукт на мировом рынке. Помимо компаний про- 
дуцентов предпринимательскую подсистему составляют группы предприятий, специализирующихся на удовлетворении внутренних нужд региона посредством перепродажи товаров и услуг.

Следующей подсистемой, оказывающей существенное влияние на региональную экономику, является социальная подсистема. Она имеет ряд стратегических задач: забота о здоровье населения; воспитание и обучение будущих специалистов; социальная защита. Развитие социальной подсистемы зависит от производственной. Социальные проекты финансируются за счет средств, которые поступают от материального производства.

Одновременно с социальной подсистемой на мировоззрение человека оказывает влияние духовная сфера, обеспечивающая развитие культурных ценностей, науки и образования. Обе подсистемы являются ресурсозатратными, но результаты этих вложений будут оценены экономикой региона в будущем.

Блок управления в региональной системе объединяет и контролирует функционирование подсистем, предметом управления в котором выступают отношения между хозяйствующими субъектами по поводу эффективного использования региональных ресурсов с целью решения социально-экономических проблем.

Представление экономической безопасности региона с позиции структурных элементов показывает, на какие элементы должна быть направлена защита от внешних и внутренних угроз.

Экономическая безопасность региона рассматривается в разрезе влияния на нее внешних и внутренних факторов [Татаркин и др., 1997: 811]. Во внутриэкономическом аспекте безопасность региональной экономики связана с природными, социальными и инфраструктурными факторами, отражающимися во внутреннем иммунитете и эластичности региона. Во внешнеэкономическом аспекте - отражает конкурентоспособность региона на рынке, зависимость от внешних материальных ресурсов (особенно продовольственных).

Экономическая безопасность региона представляет собой комплекс мер по предупреждению, минимизации последствий различных угроз. Такие угрозы традиционно делят на внешние (находящиеся за пределами территории региона и за пределами его контроля) и внутренние (на которые регион непосредственно может повлиять).

К внутренним относят угрозы, возникающие в реальном секторе народного хозяйства, в соци- альной среде, а также угрозы продовольственного и энергетического характера. В свою очередь, угрозы реального сектора экономики представляют собой спад производства, потерю рынков сбыта и основных фондов, отказ от поддержки предприятий, снижение инвестиционной и инновационной активности, свертывание НИОКР, потерю квалифицированных кадров.

К угрозам, возникающим в социальной сфеpe, относят рост безработицы, снижение уровня и качества жизни, увеличение социальных иждивенцев, потерю трудовых ресурсов. Эти угрозы имеют колоссальное значение, поскольку основным показателем для оценки уровня экономической безопасности региона является уровень и качество жизни его населения.

К угрозам, связанным с продовольственной и энергетической самостоятельностью региона, относят уровень конкуренции между отечественными и иностранными товарами, открытость рынков для импортеров, уровень диспропорции цен, падение производства энергии. В условиях международного разделения труда угроза продовольственной и энергетической самостоятельности встает очень остро. Особенно это наблюдалось в период санкций, когда отдельным регионам пришлось бороться с продовольственной нехваткой.

К внешним угрозам экономической безопасности принято относить угрозы, исходящие от других регионов страны или от политического центра, а также от других стран, территориально близких, что и обусловливает сильную связь. К таким угрозам относят валютно-финансовые, экономические и политические. Политические угрозы выражаются в навязывании мнений, сепаратизме. Выделяют два уровня интересов: интересы Федерального центра, которые представлены интересами государства, и «местнические интересы» - интересы региона. Они не всегда совпадают друг с другом, и при этом интересы государства должны приниматься как первостепенные, поскольку направлены на обеспечение безопасности страны [Буянова, Королев, 2013].

Валютно-финансовые угрозы представляют собой ошибки, возникшие из-за неточности расчетов, неэффективности использования валютных резервов, увеличения долговых операций, оттока валютных средств из региона и другие.

К экономическим внешним угрозам безопасности региона относятся в первую очередь криминализация экономики, стагнация производств, потери связей с внешним рынком, вытеснение из него, недополучение внешнего дохода. 
Кроме традиционного деления на внутренние и внешние угрозы, выделяют также реальные и потенциальные. Реальные угрозы возникают при готовности негативных факторов немедленно оказывать влияние на действие системы. Потенциальные же угрозы отодвинуты во времени, они возникнут в будущем, переходя в разряд реальных угроз [Зибарев, 2010: 325-330].

Таким образом, экономическая безопасность региона представляет собой комплекс специфических мер, способствующих устойчивому развитию всех элементов (население, природноресурсный блок, предпринимательская сфера, социальная подсистема, духовная сфера, блок управления) множественной структурной организации региона.

\section{Методика оценки экономической безопасности региона}

В настоящее время нет единой методики оценки экономической безопасности региона. Во многих случаях состояние экономической безопасности является субъективно оцениваемым. Однако для того, чтобы выстраивать систему укрепления экономической безопасности, в первую очередь необходимо иметь представление о ее уровне на данный момент, что ставит острой проблемой обоснование адекватной и оперативной методики ее оценки.

Существующие методики оценки экономической безопасности регионального пространства можно условно разделить на следующие группы: мониторинг основных макроэкономических показателей и сравнение их с пороговыми значениями, которые чаще всего устанавливаются в процессе экспертного анализа; оценка темпов экономического роста региона по основным макроэкономическим показателям, интегральным показателям и динамика их изменения; метод экспертной оценки для ранжирования территорий по уровню экономической безопасности; методы прикладной математики [Копытов, Макеева, 2014].

Для оценки экономической безопасности региона авторами был выбран метод мониторинга основных макроэкономических показателей и сравнение их с пороговыми значениями.

Метод мониторинга основных макроэкономических показателей и сравнение их с пороговыми значениями является наиболее адаптивным для регионов. Его основа была изучена в трудах современных экономистов (С.Ю. Глазь- ев, В.К. Сенчагов, А.И. Татаркин, И.Н. Петренко и др.), посвященных разработке методик оценки экономической безопасности России и ее регионов [Глазьев, 1997; Петренко, 2005; Сенчагов, 2002; Сенчагов, Иванов, 2015; Татаркин и др., 1997].

Для оценки уровня экономической безопасности региональной системы следует учитывать следующие аспекты: экономическая безопасность региона определяется основными факторами производства (с учетом их качественного состояния и доступности); экономическая безопасность региона зависит от способности системы обеспечить эффективное использование, соединение факторов производства, то есть обеспечить наивысшую производительность труда как основу устойчивого развития системы; экономическая безопасность региона обусловливается уровнем его адаптационного потенциала к влиянию факторов внешнего экономического пространства [Буянова, 2012].

Таким образом, уровень экономической безопасности региона зависит от его способности эффективной адаптации к изменениям, под влиянием внешних и внутренних факторов, а также от состояния экономического пространства, в котором реализуются экономические интересы хозяйствующих субъектов и неотъемлемой частью которого он является. Следовательно, уровень экономической безопасности целесообразно оценивать посредством «интегрального показателя экономической безопасности» (IIESS). Структурная схема интегрального показателя экономической безопасности региона представлена на рисунке 1.

Данный подход предусматривает выявление интегрированного влияния на процесс социальноэкономического развития региональной системы рыночных, нерыночных и социальных факторов.

Выбор индикаторов обусловлен влиянием различных сфер на экономическую безопасность региона. Прежде всего, на экономическую безопасность влияют факторы, связанные с производством и потреблением товаров и услуг. Их авторы предлагают выделить в первый блок: рыночные факторы. Второй блок факторов составляют индикаторы, не влияющие на рынок. Третий блок индикаторов связан с важнейшей сферой жизни социальной. Экономическая безопасность предполагает обеспечение гражданам качественного уровня жизни. Социальный блок представляют индикаторы, способные дать оценку уровня социальной обеспеченности населения. 


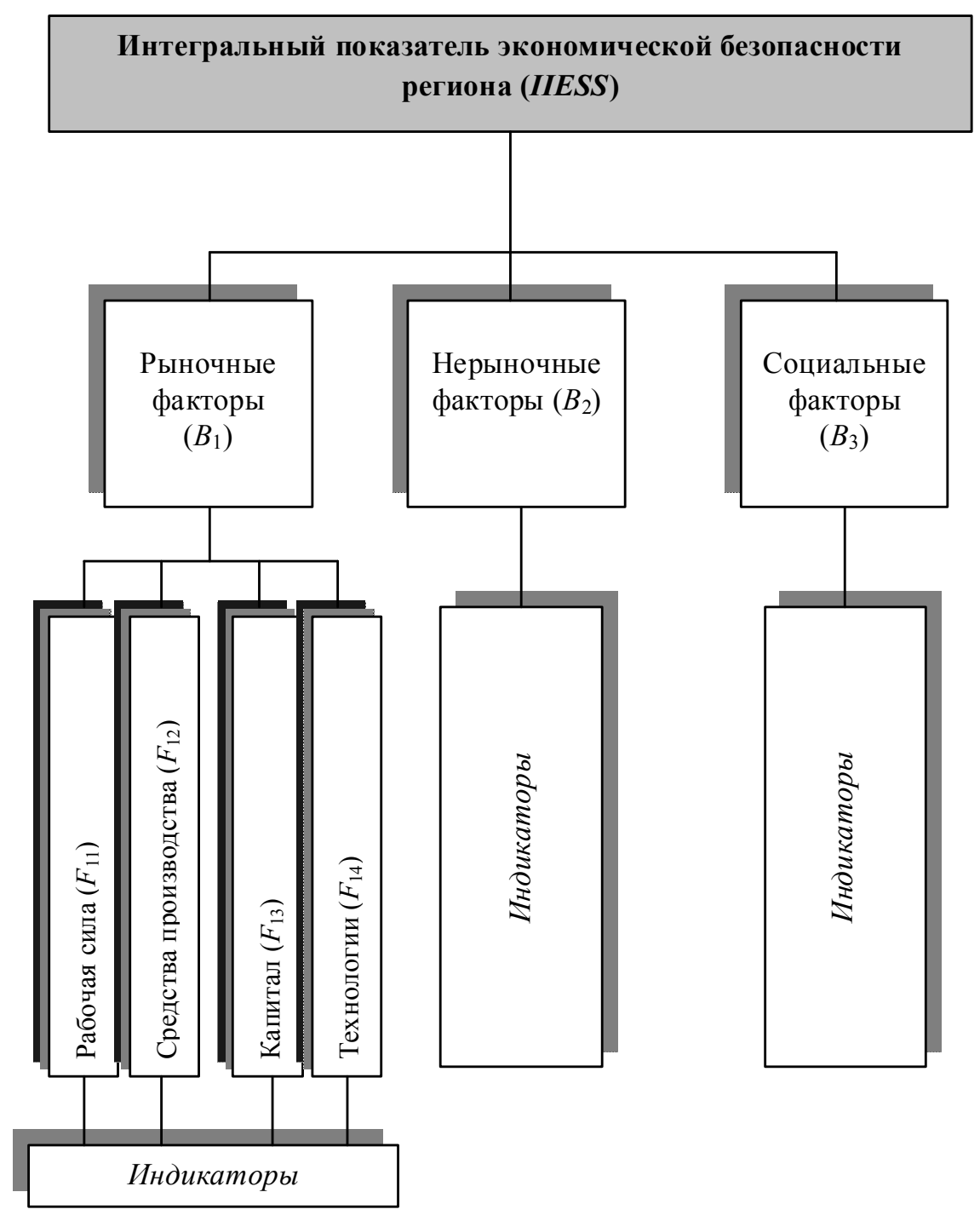

Рис. 1. Структура интегрального показателя экономической безопасности региона

Примечание. Составлено авторами.

Таким образом, структура разработанной авторами системы показателей оценки экономической безопасности региона включает:

1. Блок рыночных факторов $\left(B_{1}\right)$ :

- численность населения, занятого в экономике;

- затраты на технологические инновации на душу населения, млн руб./тыс. чел.;

- инвестиции в основной капитал на душу населения;

- стоимость основных фондов экономики на душу населения, млн руб./тыс. чел.;

- профицит / дефицит консолидированного бюджета субъекта на душу населения, руб./чел.;

- земельная площадь сельскохозяйственных угодий, \% от общей площади.

2. Блок нерыночных факторов $\left(B_{2}\right)$ :
- число государственных служащих, \% к населению;

- поступления налоговых платежей в бюджетную систему РФ на душу населения, руб./чел.;

- поступление прямых иностранных инвестиций, млн долл. США.

3. Блок социальных факторов $\left(B_{3}\right)$ :

- численность населения с денежными доходами ниже прожиточного минимума, \% к населению;

- число зарегистрированных преступлений на 10000 населения;

- уровень безработицы, \%;

- средний размер назначенных пенсий, руб.

На основе выбранных индикаторов были сформированы пороговые значения показателя экономической безопасности региона. 
В основу расчетов уровня экономической безопасности Волгоградской области положена методика расчета «Интегрального показателя безопасности экономического пространства» (IIESS) региона, разработанная И.Н. Петренко [Петренко, 2005], с некоторыми авторскими уточнениями.

$$
\text { IIESS }=\sum_{n=1}^{\delta} A_{n} \times B_{n},
$$

где $a_{n}, b_{n i}-$ факторные нагрузки блоков.

$$
B_{1}=\sum_{y=1}^{4} C_{1 y} \times F_{1 y}
$$

где $C_{1 y}$ - факторная нагрузка блока $B_{1}$, a $F_{1 y}$ - величины основных факторов.

$\Delta \mathrm{ni}$ - отклонение фактического значения индикатора Ini $n$-го блока от порогового, \% (кроме блока $\left.B_{1}\right)$ :

$$
\Delta n i=(\text { Inif }- \text { Inin }) / \operatorname{Inin} \times 100 \% \text {, }
$$

где Inif - фактическое значение индикатора Ini; Inin пороговое значение Ini; $a_{n}, b_{n i}, C_{1 y}$ - факторные нагрузки блоков, индикаторов в блоках и факторов в $B_{1}$; при этом принято, что они равны единице, величины основных факторов $F_{1 y}$ и блоков факторов $B_{n}$ рассчитываются как средневзвешенные величины.

Следует отметить, что для оценки безопасности региональной экономической системы необходимо изучать динамику показателей в сопоставлении с их пороговыми значениями. Пороговые индикаторы - это предельные значения, несоблюдение которых препятствует нормальному развитию различных элементов воспроизводства, что приводит к формированию негативных тенденций в области хозяйственной безопасности.

\section{Обсуждение и результаты}

На основании методики расчета интегрального показателя экономической безопасно- сти региона, рассмотренной выше, был определен IIESS Волгоградской области. Период исследования составляет 7 лет - с 2010 по 2017 год. Такой промежуток времени позволит оценить экономическую безопасность региона при влиянии на страну внешних угроз - западных санкций, введенных в 2014 году. За основу при разработке пороговых значений большинства индикаторов взяты средние общероссийские показатели соответствующих экономических и социальных секторов. Фактическое отклонение индикаторов от пороговых значений рассчитывалось исходя из имеющихся официальных статистических данных Госкомстата Российской Федерации.

Для удобства анализа была создана сводная таблица блоков факторов и IIESS для Волгоградской области (табл. 1).

Динамика показателя экономической безопасности Волгоградской области представлена на рисунке 2.

По результатам исследования было выяснено, что экономическая безопасность Волгоградской области на исследуемом промежутке времени имеет неоднозначную тенденцию. В 2010 г. показатель составил 26,57, такое значение приближено к среднему за исследуемый период, а значит, можем заключить, что являлось приемлемым для региона. В 2013 г. темп роста по отношению к 2010 г. составил $15,11 \%$. Волгоградская область стала экономически небезопасным регионом. Такие колебания показателя обусловлены рядом причин. Во-первых, российская экономика в 2010 г. только оправилась от кризиса 2008 г., а соответственно высоких значений показателя стоило ожидать, при условии стабильности, через 2 года. Однако без кризисов обойтись не удалось. Так, в 2012 г. из-за плохого урожая зерна сократился региональный ВВП. 2013 г. с экономической точки зрения оказался не прогрессивным.

Таблий 1

\section{Сводные индикаторы экономической безопасности Волгоградской области за период 2010-2017 гг.}

\begin{tabular}{|l|c|c|c|c|c|c|c|c|}
\hline № блока & 2010 г. & 2011 г. & 2012 г. & 2013 г. & 2014 г. & 2015 г. & 2016 г. & 2017 г. \\
\hline$B_{1}$ & 66,62 & 63,75 & 65,10 & 64,63 & 68,63 & 68,37 & 65,95 & 64,60 \\
\hline$B_{2}$ & $-40,93$ & $-43,65$ & $-41,89$ & $-46,53$ & $-35,99$ & $-31,35$ & $-40,39$ & $-38,43$ \\
\hline$B_{3}$ & 0,88 & 3,30 & 4,60 & 4,45 & $-0,75$ & $-6,16$ & $-4,37$ & $-6,27$ \\
\hline IIESS & 26,57 & 23,41 & 27,81 & 22,55 & 31,89 & 30,87 & 21,19 & 19,9 \\
\hline
\end{tabular}

Примечание. Составлено и рассчитано авторами по: [Регионы России, 2018]. 
В 2014 и 2015 гг. произошел резкий скачек показателя экономической безопасности, что противоречиво, если учитывать политический кризис, начавшийся в 2014 году. Прирост показателя в 2015 г. относительно кризисного 2013 г. составил $36,84 \%$. По мнению авторов, такая ситуация может быть обусловлена отсрочившимся эффектом кризиса, который экономика региона приняла на себя только в 2016 г., когда показатель резко упал на $31,4 \%$.

Меры властей по поддержке экономики в 2014 и 2015 гг. способствовали смягчению влияния кризисных явлений на экономику региона. Кроме того, существует временной лаг приложения угроз на региональную экономику. Однако в последние два года такие меры не сдержали появившиеся угрозы.

Для того чтобы оценить, какие из факторов наиболее сильно повлияли на изменение интегрального показателя экономической безопасности, необходимо изучить их динамику (рис. 3). Стоит также заметить, что мы рассматриваем не абсолютные значения показателей, а в отношении с пороговыми значениями, за которые были приняты их средние значения по России. Так, до 2015 г. улучшался показатель инвестиций в основной капитал на душу населения, но регион не дотягивал до среднероссийского уровня. С 2013 г. ухудшается значение численности населения, занятого в экономике. Это является следствием снижения абсолютных показателей в регионе и роста данного показателя в среднем по России. Также стоит отметить, что земельная площадь сельскохозяйственных угодий в процентах от общей площади резко упала с 2016 г., что также дает весомую долю в общем снижении показателя экономической безопасности в 2016 году. В целом можно сказать, что Волгоградская область отстает от среднероссийских показателей, и вместе с этим в некоторых проявляет отрицательную динамику. Из этого и складывается динамика блока рыночных индикаторов.

Динамика индикаторов блока нерыночных факторов (см. рис. 4) совпадает с общей тенденцией показателя экономической безопасности региона. Резкое увеличение его в 2015 г. во многом определяется снижением разницы в уровнях поступления прямых иностранных инвестиций в регион и инвестиций в среднем по России. Так, на 13,2 \% вырос данный показатель в 2015 г. по отношению к 2016 году. Также стоит отметить, что резкий рост уровня иностранных инвестиций в экономику Волгоградской

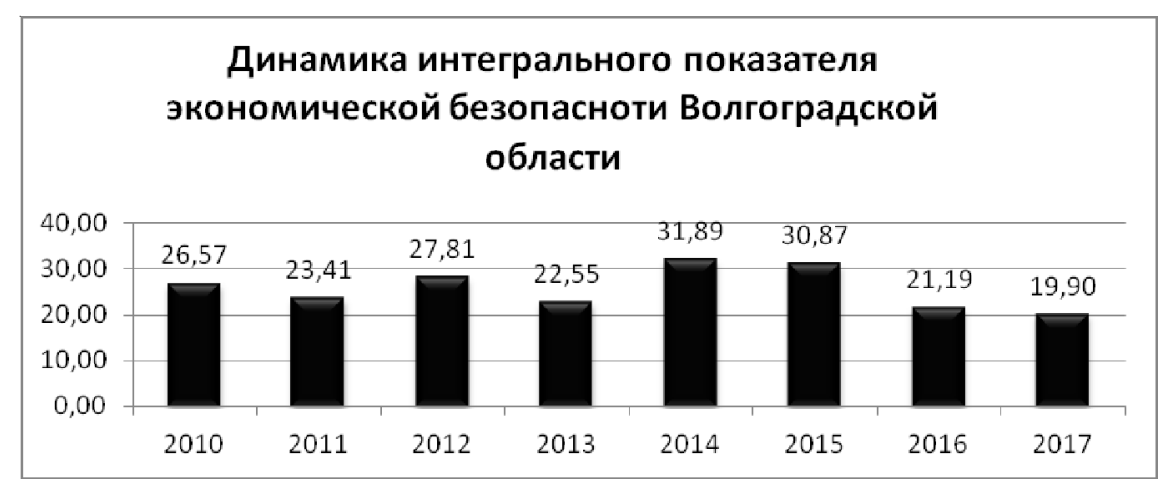

Рис. 2. Динамика интегрального показателя экономической безопасности Волгоградской области Примечание. Составлено и рассчитано по: [Регионы России, 2018].

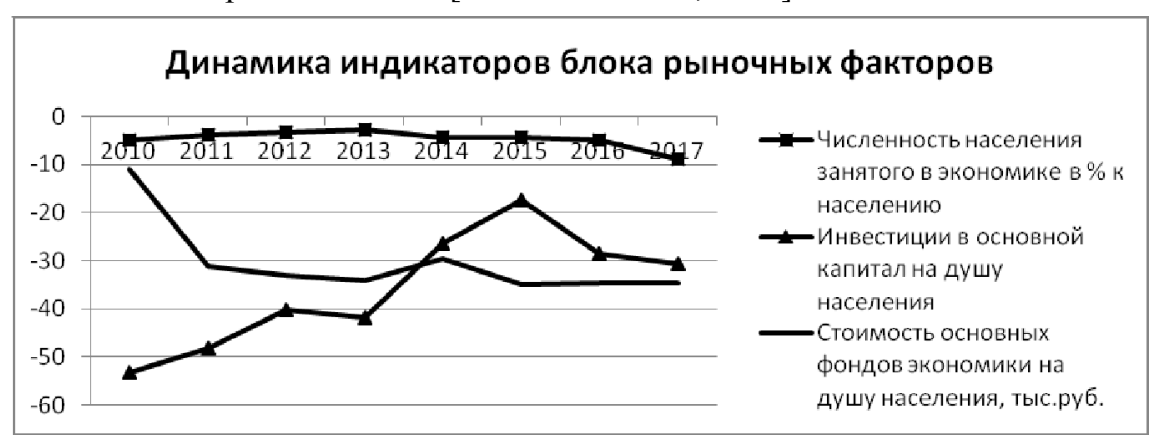

Рис. 3. Динамика индикаторов блока рыночных факторов Волгоградской области Примечание. Составлено и рассчитано авторами по: [Регионы России, 2018]. 
области наблюдался только в 2014 и 2015 гг, после чего их уровень резко упал по всей стране. Поступления налоговых платежей в бюджет росли с 2013 г. в среднем на 6,28\%, что обеспечивало положительную динамику влияния данного показателя на уровень экономической безопасности в регионе.

Таким образом, можно характеризовать уровень безопасности экономического пространства Волгоградской области как неустойчивый за счет снижения значений блока рыночных факторов.

\section{Заключение}

Подводя итог проведенному анализу интегрального показателя экономической безопасности, отметим, что Волгоградская область оценивается как небезопасный регион. С 2015 г. наблюдается отрицательная тенденция, которая говорит о развитии кризиса в регионе.

При общей стабилизации региональной ситуации структура экономики почти не изменяется, основные фонды медленно модернизируются, что накладывает ограничения на перспективы качественного роста. Одновременно с изменениями общих макроэкономических условий хозяйствования отечественной экономики (уменьшение разрыва между уровнем валютного курса и паритетом покупательной способности; удорожание рабочей силы; стремление к выравниванию с мировыми тарифов естественных монополий и выравнивание с ними внутренних цен на сырье) подвергается изменениям и портфель ресурсов области, сохраняется значительная технологическая отсталость, происходит последовательное истощение природных ресурсов. Существует риск увеличения обязательств регионального бюджета, обусловленных ростом заработ- ной платы и необходимостью вкладов в ЖКХ и социальную сферу. Это, в свою очередь, накладывает свои ограничения на оптимизацию бюджетных расходов и создание реального бюджета развития области.

Сложившаяся неоднозначная тенденция отражается на развитии предпринимательства в регионе. С 2010 по 2015 г. количество субъектов малого предпринимательства уменьшилось на 22,9 \%. Можно сказать, что это обусловлено нестабильностью в региональной экономике, а также кризисными явлениями 2014 года. К кризисным явлениям в 2014 г. в первую очередь стоит отнести именно массовую панику, уход с рынка по причине неизвестности и непредсказуемости будущей ситуации. По факту мы видим, что благодаря мерам государственной поддержки региональная безопасность, напротив, укрепилась, что создало толчок для дальнейшего развития предпринимательства. Так, с 2016 г. количество субъектов МСП в регионе увеличилось на 2,5\%. Среднесписочная численность работников также начала расти с 2016 г., однако уже в 2018 г. приобрела отрицательную тенденцию.

Отрицательные последствия действия кризиса 2014 г. начали проявляться в регионе только после двухгодового перерыва. Это отражается на ухудшении показателей работы субъектов малого предпринимательства. Отрицательные тенденции наблюдаются и за первые три месяца 2019 г.: количество субъектов МСП падает, среднесписочная численность работников и оборот малых предприятий также сокращаются. Однако необходимо отметить, что не только уровень экономической безопасности региона влияет на развитие предпринимательской среды и, следовательно, на бизнес в регионе, а существует и обратная зависимость. Бизнес формирует новые рабочие места населению, удовлетворяет их по-

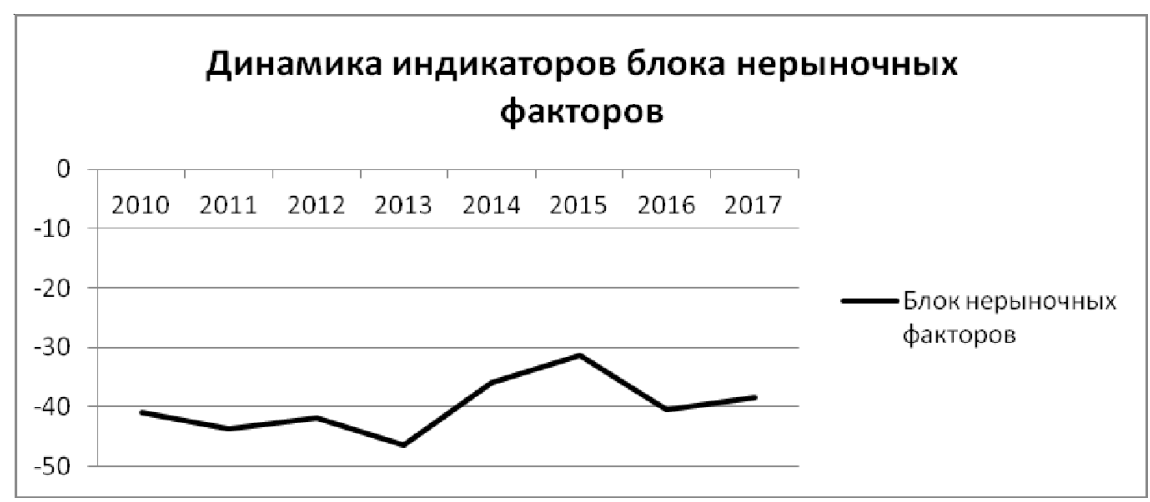

Рис. 4. Динамика индикаторов блока нерыночных факторов Волгоградской области

Примечание. Составлено и рассчитано авторами по: [Регионы России, 2018]. 
требность в экономических благах, участвует в построении конкурентной среды на рынке своего товара, формирует бюджет, а также быстро перестраивает свою деятельность, в случае кризиса, в новые отрасти.

Проведенный анализ показал, что интегральный показатель экономической безопасности системно характеризует реальную социально-экономическую ситуацию в субъектах страны и создает основу его применения в качестве механизма мониторинга безопасного и устойчивого развития в постоянно меняющихся условиях экономического пространства регионов России.

\section{ПРИМЕЧАНИЕ}

${ }^{1}$ Исследование выполнено при финансовой поддержке РФФИ и Администрации Волгоградской области в рамках научного проекта № 18-410-340002 p_a «Совершенствование институционального механизма стимулирования инновационной деятельности как основа экономической безопасности Волгоградской области».

The reported study was funded by RFBR and Volgograd Region Administration in the framework of scientific project number 18-410-340002 p_a "Improvement of the Institutional Mechanism of Stimulating Innovative Activity as a Basis of Economic Security of Volgograd Region”.

\section{СПИСОК ИСТОЧнИКОВ}

Буянова М. Э., Королев М. И., 2013. Внутренние и внешние угрозы в стратегии безопасного развития экономического пространства макрорегиона // Вестник Волгоградского государственного университета. Серия 3, Экономика. Экология. № 2 (23). С. 8-17.

Буянова М. Э., 2012. Оценка риска социально-экономического развития регионов Юга России (факторный подход) // Вестник Волгоградского государственного университета. Серия 3, Экономика. Экология. № 1 (20). С. 85-94.

Глазьев С., 1997. Основа обеспечения экономической безопасности страны - альтернативный реформационный курс // Российский экономический журнал. № 1. С. 3-16.

Зибарев М. В., 2010. Экономическая безопасность. Орск : Изд-во Орского гуманитарно-технологического ин-та. $430 \mathrm{c}$.

Копытов А. Е., Макеева Ф. С., 2014. Сравнительный анализ методик оценки экономической безопасности регионов // Науковедение : интернет-журнал. № 1 (20). URL: http://naukovedenie.ru/ (дата обращения: 30.06.2019).
Криворотов В. В., Калина А. В., Эриашвили Н. Д., 2011. Экономическая безопасность государства и регионов. М. : Юнити-Дана. 352 с.

Петренко И. Н., 2005. Безопасность экономического пространства хозяйствующего субъекта. М. : Анкил. $280 \mathrm{c.}$

Регионы России. Социально-экономические показатели. 2018. URL: http://www.gks.ru/bgd/regl/B15_14p/ Main.htm (дата обращения: 30.06.2019).

Сенчагов В. К., Иванов Е. А., 2015. Структура современного мониторинга экономической безопасности России. М. : Ин-т экономики РАН. 46 с.

Сенчагов В. К., 2002. Экономическая безопасность: геополитика, глобализация, самосохранение и развитие (книга четвертая). М. : Финстатинформ. $128 \mathrm{c}$.

Татаркин А. И., Куклин А. А., Романова О. А., Чуканов В. Н., Яковлев В. И., Козицын А. А., 1997. Экономическая безопасность региона: единство теории, методологии исследования и практики. Екатеринбург : Изд-во Уральского ун-та. 225 с.

Указ Президента РФ от 31.12.2015 г. № 683 «О Стратегии национальной безопасности Российской Федерации», 2015 // Российская газета. URL: https://rg.ru/2015/12/31/nac-bezopasnost-sitedok.html (дата обращения: 02.07.2019).

Указ Президента РФ от 13.05.2017 г. № 208 «О Стратегии экономической безопасности Российской Федерации на период до 2030 года», 2017. URL: http: //www.consultant.ru/document/cons_doc_LAW_ 216629/ (дата обращения: 02.07.2019).

\section{REFERENCES}

Buyanova M.E., Korolev M.I., 2013. Vnutrennie i vneshnie ugrozy v strategii bezopasnogo razvitiya ekonomicheskogo prostranstva makroregiona [Internal and External Threats in the Strategy of Safe Development of the Economic Space of the Macroregion]. Vestnik Volgogradskogo gosudarstvennogo universiteta. Seriya 3, Ekonomika. Ekologiya [Science Journal of Volgograd State University. Global Economic System], no. 2 (23), pp. 8-17.

Buyanova M.E., 2012. Otsenka riska sotsialnoekonomicheskogo razvitiya regionov Yuga Rossii (faktornyy podkhod) [Risk Assessment of SocioEconomic Development of the Regions of Southern Russia (Factor Approach)]. Vestnik Volgogradskogo gosudarstvennogo universiteta. Seriya 3 , Ekonomika. Ekologiya [Science Journal of Volgograd State University. Global Economic System], no. 1 (20), pp. 85-94.

Glazyev S., 1997. Osnova obespecheniya ekonomicheskoy bezopasnosti strany - alternativnyy reformatsionnyy kurs [The Basis of Economic Security of the Country - An Alternative Reformation Course]. 
Rossiyskiy ekonomicheskiy zhurnal [Russian Economic Journal], no. 1, pp. 3-16.

Zibarev M.V., 2010. Ekonomicheskaya bezopasnost [Economic Security]. Orsk, Izd-vo Orskogo gumanitarno-tekhnologicheskogo instituta. $430 \mathrm{p}$.

KopytovA.E., Makeeva F.S., 2014. Sravnitelnyy analiz metodik otsenki ekonomicheskoy bezopasnosti regionov [Comparative Analysis of Methods of Estimating the Economic Safety of Regions]. Naukovedenie: internetzhurnal [The Eurasian Scientific Journal], no. 1 (20). URL: http://naukovedenie.ru/ (accessed 30 Juny 2019).

Krivorotov V.V., Kalina A.V., Eriashvili N.D., 2011. Ekonomicheskaya bezopasnost gosudarstva $i$ regionov [Economic Security of the State and Regions]. Moscow, Juniti-Dana Publ. 352 p.

Petrenko I.N., 2005. Bezopasnost ekonomicheskogo prostranstva khozyaystvuyushchego subyekta [Security of Economic Space of an Economic Entity]. Moscow, Ankil Publ. 280 p.

Regiony Rossii. Sotsialno-ekonomicheskie pokazateli, 2018 [Regions of Russia. Socio-Economic Indicators]. URL: http://www.gks.ru/bgd/regl/ B15_14p/Main.htm (accessed 30 Juny 2019).

Senchagov V.K., Ivanov E.A., 2015. Struktura sovremennogo monitoringa ekonomicheskoy bezopasnosti Rossii [Structure of Modern Monitoring of Economic Security of Russia]. Moscow, Institut ekonomiki RAN. 46 p.
Senchagov V.K., 2002. Ekonomicheskaya bezopasnost: geopolitika, globalizatsiya, samosokhranenie i razvitie (kniga chetvertaya) [Economic Security. Geopolitics, Globalization, Self-Preservation and Development (Book Four)]. Moscow, Finstatinform Publ. 128 p.

Tatarkin A.I., Kuklin A.A., Romanova O.A., Chukanov V.N., Yakovlev V.I., Kozitsyn A.A., 1997. Ekonomicheskaya bezopasnost regiona: edinstvo teorii, metodologii issledovaniya i praktiki [Economic Security of the Region. Unity of Theory, Methodology of Research and Practice]. Yekaterinburg, Izd-vo Uralskogo universiteta. $225 \mathrm{p}$.

Ukaz Prezidenta RossiyskoyFederatsii ot 31.12.2015 g. № 683 «O Strategii natsionalnoy bezopasnosti Rossiyskoy Federatsii», 2015 [Presidential Decree of the Russian Federation of December 31, 2015 no. 683 "On the National Security Strategy of the Russian Federation"]. Rossiyskaya gazeta. URL: https://rg.ru/2015/12/31/ nac-bezopasnost-site-dok.html (accessed 2 July 2019).

Ukaz Prezidenta RF ot 13.05.2017 g. № 208 «O Strategii ekonomicheskoy bezopasnosti Rossiyskoy Federatsii na period do 2030 goda», 2017 [Presidential Decree of the Russian Federation of May 13, 2017 no. 208 “On the Strategy of Economic Security of the Russian Federation for the Period till 2030"]. URL: http://www.consultant.ru/document/ cons_doc_LAW_216629/(accessed 2 July 2019).

\section{Information about the Authors}

Marina E. Buyanova, Doctor of Sciences (Economics), Professor, Head of the Department of Economic Theory, World and Regional Economy, Volgograd State University, Prosp. Universitesky, 100, 400062 Volgograd, Russian Federation, buyanovam@rambler.ru, https://orcid.org/0000-0003-1052-3780

Irina S. Averina, Candidate of Sciences (Economics), Associate Professor, Department of Economic Theory, World and Regional Economy, Volgograd State University, Prosp. Universitesky, 100, 400062 Volgograd, Russian Federation, AverinaIS@volsu.ru,https://orcid.org/ 0000-0002-1100-3421

Alina S. Kulakova, Master Student, Department of Economic Theory, World and Regional Economy, Volgograd State University, Prosp. Universitesky, 100, 400062 Volgograd, Russian Federation, kulakova.lina@list.ru, https://orcid.org/0000-0002-2724-2937

\section{Информация об авторах}

Марина Эдуардовна Буянова, доктор экономических наук, профессор, заведующая кафедрой экономической теории, мировой и региональной экономики, Волгоградский государственный университет, просп. Университетский, 100, 400062 г. Волгоград, Российская Федерация, buyanovam@rambler.ru, https://orcid.org/0000-0003-1052-3780

Ирина Сергеевна Аверина, кандидат экономических наук, доцент кафедры экономической теории, мировой и региональной экономики, Волгоградский государственный университет, просп. Университетский, 100, 400062 г. Волгоград, Российская Федерация, AverinaIS@volsu.ru, https://orcid.org/0000-0002-1100-3421

Алина Сергеевна Кулакова, магистрант кафедры экономической теории, мировой и региональной экономики, Волгоградский государственный университет, просп. Университетский, 100, 400062 г. Волгоград, Российская Федерация, kulakova.lina@list.ru, https://orcid.org/0000-0002-2724-2937 